\title{
Phenylephrine and paradoxically increased muscle tissue oxygenation: is the mechanism related to local venoconstriction or augmented venous return?
}

\author{
Hilary P. Grocott ${ }^{1}$
}

Received: 9 January 2018 / Accepted: 12 January 2018 / Published online: 16 January 2018

(c) Springer Science+Business Media B.V., part of Springer Nature 2018

To the Editor,

The recent study by Sørensen et al. [1] outlining the apparent increase in near-infrared spectroscopy (NIRS)-measured muscle oxygenation $\left(\mathrm{SmO}_{2}\right)$ during phenylephrine infusion proposes that the increase is a function of muscle venoconstriction. As the NIRS $\mathrm{SmO}_{2}$ signal is typically derived assuming a fixed ratio of arterial:venous hemoglobin, decreasing the venous component (due to venoconstriction) would increase the more oxygenated arterial component with a resulting overall increase in $\mathrm{SmO}_{2}$. Although this could very well be the mechanism at work, the NIRS device that was used in their study (Invos 5100, Medtronic, Dublin, Ireland) uses an algorithm in which the arterial:venous ratio of blood is fixed and is based on that derived from studying the brain $[2,3]$, not skeletal muscle, adding uncertainty to this proposed mechanism. Additional uncertainty is that the increase in $\mathrm{SmO}_{2}$ could also have been simply a function of an increase in venous return, which the $\alpha$-adrenergic agonist phenylephrine is known to affect by augmenting the stressed component of the venous compartment [4], and consequently the cardiac output which could increase oxygenation of the muscle. Indeed, the demonstration by Sørensen et al. that the collapsibility index of the inferior vena cava (IVC) was reduced with the use of phenylephrine further supports the notion that the drug may have augmented venous return (and consequently IVC volume).

In order to enhance confidence in their muscle venoconstrictive theory, one would first need to better document the relative percentage of arterial to venous blood in the skeletal muscle and calibrate the NIRS device based on the

Hilary P. Grocott

hgrocott@sbgh.mb.ca

1 Department of Anesthesia, Perioperative and Pain Medicine, University of Manitoba, CR3008 - 369 Tache Avenue,

Winnipeg, MB R2H 2A6, Canada muscle bed that was being interrogated. Furthermore, their data indirectly suggests that augmentation of venous return was also a possibility for the increased muscle oxygenation. Theoretically, this could have been investigated if flow catheters had been inserted into the various venous vessels draining the muscle tissue bed of interest, though admittedly, this might not have been logistically feasible.

Author contributions HG contributed to the concept and the writing of this letter.

\section{Compliance with ethical standards}

Conflict of interest Hilary P. Grocott declare that he/she has no conflict of interest to disclose.

\section{References}

1. Sorensen H, Thomsen JH, Meyer ASP, et al. Phenylephrine increases near-infrared spectroscopy determined muscle oxygenation in men. J Clin Monit Comput. 2017;31:1159-66.

2. Zheng F, Sheinberg R, Yee MS, Ono M, Zheng Y, Hogue CW. Cerebral near-infrared spectroscopy monitoring and neurologic outcomes in adult cardiac surgery patients: a systematic review. Anesth Analg. 2013;116:663-76.

3. Greenberg S, Murphy G, Shear T, et al. Extracranial contamination in the INVOS $5100 \mathrm{C}$ versus the FORE-SIGHT ELITE cerebral oximeter: a prospective observational crossover study in volunteers. Can J Anesth. 2016;63:24-30.

4. Gelman S, Bigatello L. The physiologic basis for goal-directed hemodynamic and fluid therapy: the pivotal role of the venous circulation. Can J Anesth. 2017. https://doi.org/10.1007/ s12630-017-1045-3. 